\title{
Teaching with Inspiration; the Challenges of Motivational Factors within the Educational Sector in the Kurdistan Region of Iraq
}

\author{
Ismail Noriey
}

Department of English, College of Languages, University of Human Development Sulaimani, Kurdistan Region - Iraq

Ismail.noriey@uhd.edu.iq

\section{ABSTRACT}

This research paper investigates the significance of motivational factors to inspire teachers in the Kurdistan Region of Iraq. The aims of this study are defined as the following: first to highlight the importance of motivation that has an inordinate character in encouraging teachers to teach successfully. Second, the significance of teaching with pleasure has an impact on students' performances. This study involved a mixed-method approach and was conducted in two stages: first, the researcher gathered qualitative data by conducting individual interviews. Second, the researcher collected quantitative data by managing a questionnaire for students. To investigate this matter, an experimental study was conducted with the participation of 153 students from 5 colleges of 2 universities in the Kurdistan Region of Iraq. 24 teachers were interviewed from 5 colleges and 2 universities in the same region. The findings exhibited in this study that the nature of motivational factors is sophisticated and it is a keystone for an effective teacher to obtain it effectively. In conclusion, the findings show that the motivational factors have more critical indicators of the literature reviews and descriptive methodology that is solid for data analysis.

Keywords: motivation, motivational factors, effective teacher, approaches, intrinsic, extrinsic

Cite this article as: Noriey, I. (2021). Teaching with Inspiration; the Challenges of Motivational Factors within the Educational Sector in the Kurdistan Region of Iraq. International Journal of Higher Education Pedagogies, 2(2), 38-52. https://doi.org/10.33422/ijhep.v2i2.57

\section{Introduction}

Nowadays, arguably every teacher is different; each has their backgrounds and the culture that make them unique. Therefore, to understand what is teaching with pleasure; the challenges of motivational factors in the Kurdistan Region of Iraq to investigate the importance of motivation (intrinsic and extrinsic) that has a prodigious role in encouraging teachers to teach inspirationally and the impact of students' performances. According to Sucuoglu (2007), he elaborates that, "the concept of motivation fits in almost every field and this is why it occupies a special position in the teaching and learning process" (p.73). Accordingly, it is part of teachers' techniques, teaching style, and teacher's art to give their best abilities that students are able to achieve their goals and they are staying motivated to learn. Consequently, the diverse approaches to motivate teaching and learning can focus on cognitive behaviours and non-cognitive aspects.

(C) The Author(s). 2021 Open Access. This article is distributed under the terms of the Creative Commons Attribution 4.0 International License, which permits unrestricted use, distribution, and redistribution in any medium, provided that the original author(s) and source are credited. 
This study has split into three main parts; the first focuses on; the motivational factors and strategies used by Kurdish teachers in Iraqi Kurdistan Region. The paper has crucially discussed and assessed the main major motivation in both intrinsic and extrinsic factors according to the literature. In the second part, the researcher believes that there is no single paradigm that could satisfactorily deal with all of the required methodological aspects. In order to have a justification as a mixed methods researcher, and I used mixed methods to show study of fact that is based on ontology and epistemology. This mixed methods research has been practiced since the 1950s, but formally began in the late 1980s. Additionally, it progressively used by a rising number of researchers such as (Creswell, 2003, Plano Clark 2007, and Crooks 2008). It is significant to recognize the apparent value of combining two different methodologies, particularly assumed the added resources, time, and proficiency required to conduct a mixed methods study.

The growth in mixed methods research allows the researcher to accomplish an understanding the question of defining the perceived value of mixed methods research associated with a morally quantitative or virtuously qualitative study. The reasons that a researcher has used mixed methods to evaluate the value of objective and subjective knowledge.

Finally, in section three, the researcher transitorily discussed the findings. This study has focused the two main research questions;

1) What are the challenges of the motivational factors into inspiration in teaching?

2) What are the most significant influences in teaching that makes him/her an effective teacher for improvement?

\subsection{Research Objectives}

- To investigate the impact of the most significant keystone in teaching that makes them on an impactful teacher.

- To explore and critically discuss the challenges of the motivational factors into encouraging teaching?

- To identify most of the difficulties that are facing teachers to grasp the motivational factors.

- To suggest implementable suggestions for improving the current situation.

- To examine the motivational factors of teachers, and students' accomplishments

\section{Literature Review}

This section has three aims: 1) An understanding of the concept of the idea of motivation and motivational factors. 2) A discussion on the concepts of the significance and the limitation of the study. 3) A good evaluation of the review of the literature.

\subsection{What is Motivation in Education?}

According to Pmbok (2009), motivation is the municipal that can sustain students' devotion and behaviour over and above provides with more energy to wanted to lead tasks to achievement. Consequently, it can help tolerate activities over a period of time. Nevertheless, in education, motivation can have a diversity of impacts on students' performance, behaviour, encouragement and achievement. 
Additionally, the enthusiasm was encouraged by the Latin term "Move" for the first time, which means undertaking and it is an English word. Motivation can be well-defined to be "the reason that guides behaviour" (Guay et al., 2010, p.712). Other researchers like Gredler, Broussard and Garrison (2004) mostly identified that motivation is a process of collaboration between the student and the environment, which is noticeable by increase, range, initiation, or tenacity of goal-directed behaviour. Moreover, it has been assumed of multifariously as a quality of the individual, the circumstances, or the movement in which the individual involved. Conversely, William (2009) stated "enthusiasm is unity of the greatest significant aspects distressing human behaviour and routine by stimulating it and generous path towards the chosen areas. It is the internal need or energy ended by individuals to accomplish their mark and gratify individual's desires (p.88).

\subsection{Types of Motivation in Education}

According to Boima (1997), the motivation of students involves the four types of motivation are extrinsic, identified, intrinsic and introjected, which are affecting on students' performance, achievement, and encouragement in the learning process. (p.11). In addition to, students who are a reduced amount of inspired or disconnected. In contrast, "are passive, do not try to solve difficult problems and challenges, and they give up easily" (Skinner \& Belmont, 1993, p.4). Afterward, student inspiration is often alienated into two types as the resulting:

\section{- Tangible Motivation}

According to Dev (1997), "a student who is motivated from within will not need to give any type of reward or incentive to state or complete a task. This type of student is more likely to complete the task of selecting and is impressed by the nature of activity" (p.33). Additionally, this type of motivation can be defined to be tangibly inspired when he or she is motivated in the classroom. It helps students to learn new knowledge, to gain a reward, or to avoid a punishment. This type of motivation is a critical element in promoting learning. Nevertheless, there are motionless many teachers who desire to use forms of motivation techniques which may cause students to be unenthusiastic.

\section{- Intangible Motivation}

As stated by Dev (1997), this type of motivation are not physical items but extremely valuable in the classroom, and something student or learner can experience. For instance, teacher professional attitude can impact on their student's behaviour such as how to thank them, and how to interact positively with other classmates in the classroom or the whole school. Moreover, it can be used to encourage student throughout an activity or task, showing them that they are behaving appropriately and supporting them the confidence to continue.

According Brooks, (2009) pointed out "receiving appreciation for academic success of the student; excellent attendance record, warm praise, thanks and smiles frequently throughout every day, it would be success on students' academic performance (p.91). 


\subsection{Motivational Factors}

This study has discussed the motivation factors are related to tangible and intangible motivation.

Currently, there are several questions like "what is motivation", "why motivation is significant" how the teachers' self-motivation directly affects students' performance and academic achievements"? It is vital to understand the motivational factors, as stated by Brooks (2009) "motivation plays an important role in the school because it increases teacher performance and self-esteem can be achieved in a resourceful way. The behaviour of teachers can be change through motivation in any school" (p.88). Additionally, the examination that continues to be responded is that as a substitute of having magnetisms in the other careers what are the factors which central to implement the teaching career successfully? It is assumed that those work as a teacher is not cautiously sound like the associate in the other professions. Finally, this study discussed whether the question has moved from motivation is a key factor for teaching and learning with preference to what creates motivation and how teachers and classrooms.

\subsection{Statement of the problem}

The study was premeditated to classify the motivational factors accountable for the teaching career as a professional job. This is to explore the motivational factors impact on teachers' performance in teaching with desire; the challenges of motivational factors in the Kurdistan Region of Iraq (KRI). Lastly, according to Noam (2013) stated "it is vital to identify the significant of motivation that has a great role in encouraging teachers to teach successfully" (p.55).

\subsection{Significant of the Study}

For the last 50 years, the educational sector in the world wanted to response the question, what are the motivational factors can encourage professional teacher to teach with inspiration in the classroom. According to Boima (1997), that pointed out "the high motivation and commitment to learning have been consistently associated with reduced failure and higher levels of students in school" (p.83). Moreover, the two main points that it makes this study is significant are; first, to identify the motivational factors accountable for selecting the teaching career by the teachers. Second, the compassion of these factors will assistance eliminate flaws in teaching career that impacts teacher's performance a significant role in motivating students in the classroom, which lead the learning process of the student's achievement.

\subsection{Limitation of the Study}

The limitation of the study was surrounded to individual one public university and one private university in university in the Kurdistan Region of Iraq. The reasons behind this that most of the participations from other universities were declined to take part of the study.

\subsection{Review of Literature}

According to Margetts (2007), pointed out "the indirect with motivation, obligation is perceived in the literature to be equivalent significant in accomplishing high consequences in 
learning (p.28). Moreover, as stated by Russell (2005), that "teaching with ambition support to involve students in learning, performance, success, encouragement, and reach higher academic achievements (p.66). Furthermore, motivation decreases absenteeism and will be stimulated self-confidence. According to Zyngier (2008), stated: "it is one of the greatest achievements of teachers because this leads to higher academic achievement throughout life" (p.88).

\subsection{Improvement of Motivational Factors in Education}

According to Margetts (2007), motivational factors have several effects on the learning and behaviour of students. First, motivation leads behaviour to specific goals; such as students' engagement in the classroom. Second, motivation sets specific influence on students' performance and academic achievement. Furthermore, as stated by Maehr (2003) motivation is the state that can sustain students' consideration and behaviour as well as make great achievement in the academic performance. Additionally, on the word of Dornyie (2009), there are three main stages of the motivational factors in the last 50 years in the educational sector. First Dornyie classifies them as the social emotional dated during the year (1959-1990), has pointed out the awareness of consolidative and influential enthusiasm was considered. Second, in the cognitive-positioned dated (during the 1990s), the educations had in progress in which autonomy and self-possession were publicized. Third, the innovative styles (past decade), that examines the knowledge of "thinkable identities" (Dornyie, 2009, p.17).

Oppositely, Lambert (1994) pointed out a wide classification of motivational factors into two types, integrative and active. Conversely, in the early (1990s) two new methods were announced and discovered by Richard (1996), which is based on exterior and interior motivational factors. Additionally, Dornyie (2009) pointed out the motivational factors can impact teacher's self-motivation, self-confidence, self-esteem, and self-respect, which lead a major achievement in the academic results. In addition to Dornyie (2009), added the link of motivation with the possible responsibility which signify what a student picture to be in the future profession within the qualified for the job" (p.17). This study suggests that motivational factors leading the significant challenging in the learning environment.

Equally, the increasing attention of student's performance in the school/ college/ university and their inspiration immaculately has developed a problematic challenge in the educational sector in the KRI. This stimulates stand up not only for standing educators but similarly for new educators and new professional practitioners in the educational sector in the KRI. Besides, as stated by Lumsden, (1994), agreed that several aspects support improved learner attention on academic results and the equal of obligation to the learner in education. Therefore, instructors/ teachers/ tutors have regulators over several of these aspects (p.35). As an alternative, when the school did a poor performance that led to the failure which is the basis for affecting advancing is formed at this stage. Hence, teachers/ instructors/ tutors must keep learners motivated within two types of motivation collected tangible and intangible.

Furthermore, Lumsden (1994) pointed out that the first inspirations in encouraging the student/learner/pupil to learn are the parents and extra associates of the family surrendering. When the student enters school/college/ university, and the level of learning, performance, 
teachers, environment and their classmates (p.56). Similarly, Manuel and Hughes (2006), pointed out recognized that teachers must remain meaningfully engaged to teach the subject of their personal and to teach professionally in the different schools/ colleges, with the student to make the transformation in their lives as essential motives for the student to select teaching and learning. This is stated by Maehr (2003) resolved that school enhancement efforts were mostly anxious with the attention and necessity of teachers, which is involved salary status; teachers' respect; self-confidence, and rewards for viewing the good performance (p.47). Finally, Adam \& William (2009) investigated by starting educators/teachers explored that teaching interests inspire students so that their academic achievement may be enhanced. This is agreed by Julie (2008) that a teacher's desire it makes a social contribution to inspire students effectively and this leads to a major improvement in the personal utility value and prior teaching.

\section{Methodology}

This section has discovered the choice of research method and discusses what methods are the most appropriate. It is significant to focus on the methodology in the interior an ontological situation and the epistemological as both impact how the methods are addressed in this study and the researcher focused on the reflection of the philosophical underpinning in education.

\subsection{Research Methodology and Methods}

As stated by Comte (2000), pointed out that to decipher knowledge beginning the research is base: three research approaches should be considered and understandable by the researchers: quantitative, qualitative and mixed methods. Besides, Creswell (2007) defined a methodology as "the precise procedures used to identify, process, select and analyze data about a topic, but in a research paper, it allows the researcher to critically evaluate a study's overall validity and reliability" (p.43). Additionally, the researcher of this present study believes each research has its strengths and weaknesses. However, commonly speaking in the educational sector there are varieties of research methodologies with no solitary recognized research methodology applicable to all research problems. Finally, the present study seeks to answer the main research questions already revealed in part one. The mixed-methods have used in this study, through this paradigm, the individual conflict of qualitative or quantitative or both as a mixed method. To conclude, the researcher decided of this study to use both lines of inquiry that simply study can combine the ontological and the epistemological position.

\subsection{The Significant Three Approaches}

Comprehensively, this study has deliberated the three major approaches that are advanced in most of the research in the educational sector. Incontestably, the three approaches are not separate as they initial give the impression.

\section{- The Qualitative Research Review}

According to Creswell (2007) stated that interviews are most effective for qualitative research and qualitative research interviews are depth interviews. Moreover, it is a method to explore 
and consider the meaning of persons or groups attribute to an as communal or human problem in the educational sector. Conversely, as stated by Lecompte, \& Schnesul (1999), this approach may be collected by perceiving applicants or places of research that gathering documents from school or college or university. Finally, the study of the qualitative data stereotypically follows the track of gathering the words or images into types of information. The outcomes of qualitative methods are more descriptive and the inferences can be drawn fairly simply from the data that is gained.

\section{- The Quantitative Research Review}

As stated by Thomas (2009), that "quantitative data includes closed-ended information such as that found on attitude behaviour or performance instruments" (p.19). Moreover, the purpose of quantitative research is to obtain knowledge and make a good understanding of the social world in particular in the educational sector. Finally, the gathering of data in this method involves using a specification information and it is an approach for objective theories by investigating the human problem. Lastly, this approach is the process of collecting and analyzing numerical data.

\section{- The Mixed-Methods Research Review}

According to Robson (2002), pointed out it is a significant approach to the review involving gathering both qualitative and quantitative data integrating the two forms of data using a different design that the researcher involves philosophical assumptions and theoretical frameworks (p.45). This present study has used the mixed-methods which is the core assumption of this form of inquiry is the mixture of both approaches.

\subsection{Choice of Methods in Education Research}

On the word of Creswell (2007), that methods are the tools and techniques that are used in the collection and analysis of data. The philosophical background of research can determine the types of methods that are appropriate. Instead, Blakie (2000) pointed out the data in educational reviews and status studies are composed by using various tools of study. The tools of investigation mostly used are questionnaires, attitude scales and interviews, casestudy, rating scales and observational techniques. Furthermore, according to Robson (2002), positivistic and interpretive paradigms are essentially concerned with understanding phenomena through two different lenses. Positivism attempts for objectivity, quantifiability, probability, and the structure of behaviour; the interpretive paradigms strive to understand and interpret the world in terms of human problems in the educational sector.

Additionally, this present study has discussed the choice of approaches that will be influenced by ontological and epistemological assumptions. According to Creswell (2007), pointed out that several convinced methods are inextricably bound up with certain ontological and epistemological assumptions (p.17). For instance, the researcher questioning a passionate coherent choice academic of the paradigms to recognize research may involve a variety of methods and various aspects of education together with teaching methods, student learning and classroom dynamics. The significant point is the researcher who engagements a specific method in a particular technique, and thus, connecting it with a precise set of ontological expectations. Conversely, as stated by Newman (2000), mixed-methods research is a feature 
of this range because it incorporates elements of both quantitative and qualitative. Finally, the researcher of this study has used the mixed-methods as a style to the inquiry involving collecting both qualitative and quantitative data this may involve philosophical expectations and hypothetical frameworks.

\subsection{The Methods of Data Collection}

The researcher of this study has used the mixed-methods to obtain responses to the main research questions and evaluate their suitability under different situations in the educational sector in the KRI. Hence, to investigate this matter, an experimental study was conducted with the participation of 153 students from 5 colleges of 2 universities in the KRI. 24 teachers interviewed from 5 colleges of 2 universities in the same region. To statistically establish most of the difficulties challenges in the motivational factor that teachers faced in the educational sector; school, college and university.

\section{- Participants}

For this study, 153 students were optionally selected from 2 universities in Kurdistan Region Iraq for a questionnaire from schools/ colleges/ universities in the Kurdistan Region Iraq. The students were at the $1^{\text {st }}, 2^{\text {nd }}, 3^{\text {rd }}$ and $4^{\text {th }}$ stage at the University, and from school's years 10,11 , and 12 within high schools during the academic year 2019-2020. Oppositely, 24 teachers interviewed from 5 colleges inside 2 universities in the same region.

\section{- The Data Collection Techniques in Education}

This study has used the mixed-methods of data collection; interview and questionnaire. The researcher assumes the two useful approaches of this study is required because only 24 teachers were accepted to be interviewed and this is not satisfactory data to be responded the main research question in-term of the ontological position. Thus, the researcher decided to have a questionnaire for the other participants and he stayed in all the 5 colleges and 2 universities personally and administered all the questionnaires among respondents. The selected candidates were separated up into two groups; the first group (A) they were interviewed and the second group (B) they have only accepted the questionnaire.

\section{- The Data Collection Analysis}

According to Kyale (1998), pointed out a researcher used a structured interview because it usually deprives researchers of the prospect to "add or remove questions, transformation their system or modify the wording of research questions" (p.18). Data gathering is the process of collecting and measuring the data obtained were organized by using a numerical technique such as a mean score. This is concluded with a methodically established system to evaluate outcomes by answering the main research questions. Moreover, the data collection analysis and interpretation of data, conclusions were drawn from the mixed-methods and recommendations were made. Finally, this study used self-completion a questionnaire created by Google and then the respondents can fill it out on their own, and saving time. The methods of data collection used in this study questioned the same research questions. Data were collected first using the interview and the second questionnaire. 


\section{- Procedures of This Study}

This present study applied accomplishment research to investigate the importance of the challenges of motivational factors in the interior educational sector in the KRI. This action research is used because it reflects education communicated in the colleges and universities in directly anxious with the excellence of educators. Furthermore, as it is collectively recognized that educators play an important person in the training and knowledge process. Educators' inspiration straight affects students' interest and abstract accomplishments. The study started at the opening during the year 2019-2020. Additionally, the teachers and students were formally knowledgeable that they are contributing to this study. They were through an ongoing process of reflection and enhancement. This method supports teachers and students expand their understanding of the challenges of motivational factors that impact teaching with inspiring in a system that is applied, reachable and advanced in their future.

\section{- The Population of Sample in Education Research}

This study is education research and the population of this paper 24 teachers interviewed from 5 colleges of universities in the KRI and distributed 153 questionnaires to students in classes based on colleges and universities in the same region. The interviews were participated by 24 teachers exasperated to obtain the view of teachers on the approaches they use to encourage students in the classroom. Furthermore, the researcher selected 153 candidates from 2 universities to fill out the questionnaires in classes. The aim is to obtain their view about the behaviour of teachers and the several ways they use in encouraging the class. The questionnaire has designed effectively which can easily to fill out during the class time. Finally, permission was obtained from the colleges and universities to get teachers acceptance to participate into the research, accomplish a review on the students.

\section{The Findings and Discussion}

The main purpose of this section is to present the data analysis procedures used to study the challenges of the motivational factors in the educational sector in KRI. It has described the implication of the findings in light of what was already known about the research problem being investigated, and explain any new understanding of the interpretation into consideration. The responses for each research question were addressed into the main parts which comes from interviews and questionnaires. In the direction of avoiding the candidate's interviews identification, this study was referred to as A1 to A24 and the 153 participants for the questionnaire were identified B1 until B 153.

\subsection{The First Main Research Question}

What are the challenges of the motivational factors into inspiration in teaching?

The findings of research question one was very interesting that shows the most challenges motivational factors to inspire in teaching within colleges/ universities. Table (1) has shown the five main challenges in which 21 out of 24 candidates' interviews were mentioned similarly. 
Table 1.

The five main challenges

\begin{tabular}{|l|c|}
\hline The Five main Challenges & Total $(\mathbf{n}=\mathbf{2 4})$ \\
\hline Readiness: Self-confidence & 23 \\
\hline The pleasure of teaching & 22 \\
\hline Tangible and Intangible motivation & 22 \\
\hline Create a Mindset & 20 \\
\hline Incessantly Professional Relationship & 21 \\
\hline
\end{tabular}

In table 1, it shows the outcomes from responses to the first research question in which there are five challenges of the motivational factors that were recognized that encouraging teacher's self-confidence to teach in diverse environments. First is self-confidence, the majority (23 out 24) of teachers' respondents' have the luck of keenness in which selfconfidence. The keenness is extra related to features such as poor academic performance in colleges or universities in a lack of confidence, ongoing stressful life, articulating thoughts, poor communication skills, and having interesting keenness to learn. Besides, the second challenge is choosing the pleasure of teaching and most of the respondents '(22 out of 24) that they have mentioned. This is similarly discussed in the literature review, according to Russell (2005) that pointed out "the classroom should be a place for light hearts as well as serious minds" (p.56). Moreover, the third challenge is tangible and intangible motivation in the educational sectors. This is a very interesting outcome from this study because they were (22 out of 24) candidates who initiate complications to stability the equilibrium tangible and intangible motivation in the teaching situation.

A 13 mentioned that "it is tough to imagine effective teachers who not have an abiding attraction with their subjects, who do not love being among students, and who do not gain fulfilment from nourishing others' minds and lives". Questionably, A 24 pointed out a similar problem of A 13. In addition to, A 16 stated that "as a teacher, a parent and as a citizen we all have dark moments of the soul, times where things seem overwhelming and difficult to have self-motivation. It is as times like these that a letter like the one you wrote, both surprising and touching in its unsolicited largeness of heart, mean so much". The fourth challenge shows in the table 1 , is to create a mindset. Most participants have revealed, which is 21 out of 24. A 17 has stated "an optimistic mind can bounce me supplementary confidence that cannot start the day with a positive declaration. Conversely, A 9 has revealed that "I always get disappointed when I do not have a good balance of mindset that led me to drop selfconfidence".

On the other hand, the five challenges shown in table (1) is an incessantly professional relationship in teaching with inspiration. As it shows from the table above 22 out of 24 teachers' have stated this a main challenge of the motivational factors into inspire in teaching. Possibly, A18 pointed out that "an understanding of the type of relationship needed. Just as it's important to recognize that relationships need a clear basis, and update professionally. This is similarly addressed in the literature review, Smyth (2007) has arguably pointed out "if teachers want to achieve high results in their colleges or universities, they should first increase the student's engagement and use types of motivation in the classroom. Furthermore, they should listen to what the students want to say and maintain excellent communication 
with them (Russell, 2005, p.72). Equally, the teachers' interviews were revealed regarding when the researcher asked "which of the teaching methods in the classroom motivates students? 55\% of teachers responded that the method with a student at the centre has more value. Also, $27 \%$ assess the teacher-centred approach, and $18 \%$ think it is a mixture of both.

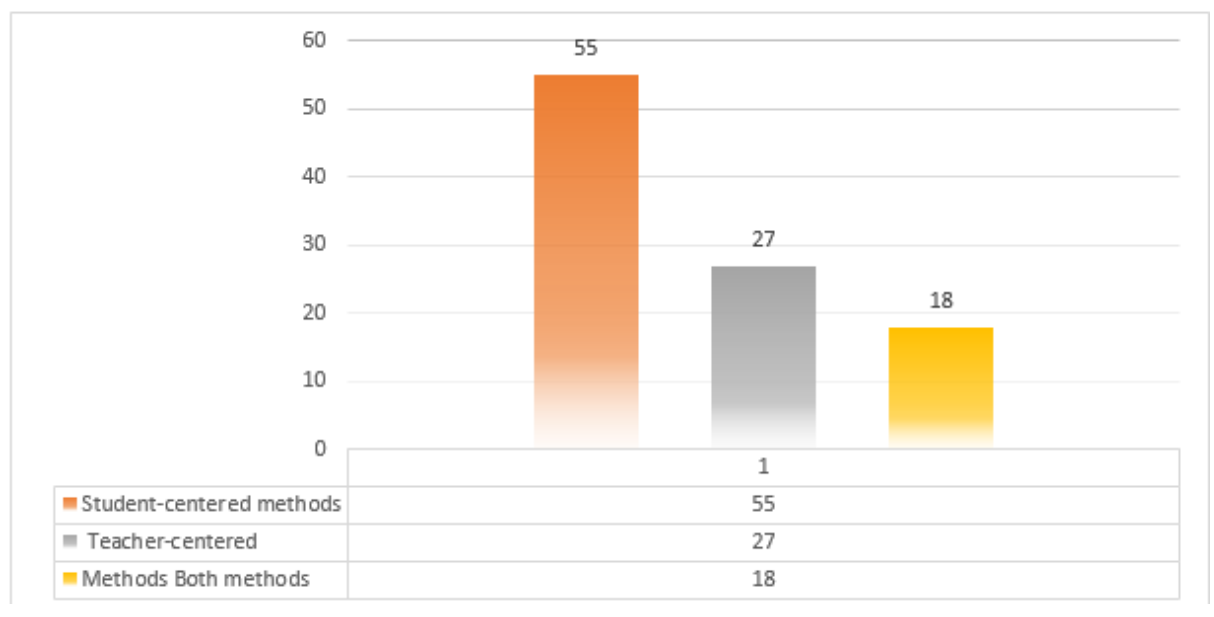

Figure 1. The teaching methods in the classroom motivates students

\subsection{The Second Main Research Question}

What is the most significant influence in teaching that makes him/her an effective teacher for improvement?

The findings of research question two show that there are several significant impacts on improving teachers' effectiveness and motivational factors to motivate students in the classroom. From Figure 2, it develops strong and concise that nearby remain 4 main important that influences improving the ways of motivation, teachers' opinion. The methods that use to motivate students in the classroom. In the second question, the researcher asked "which methods a teacher use to motivate students in the classroom? The majority of teachers' respondents' have using continual assessment ((13 out of 24$)$, which means more than $63 \%$ of educators answered that they appraise undergraduates grounded on their performance yearly. Additionally, (18 out of 24) teachers responded $19 \%$ amount the students by testing, and $11 \%$ rate the students' records. Lastly, $7 \%$ rate the students by other further methods of assessment.

Moreover, A23 mentioned that "I have argued that my self-reflection to define my motivational factors and which tools to support teachers encourage students in the classroom."

Additionally, A18 pointed out:

"In my view, there are several matters that need to consider by teachers at the starting of the undergraduate students such as; the accurate supervision of motivation that encourages students in the classroom, the correct guidance of the teaching courses, and teachers should use strong tools in teaching to avoid the misinterpretation the tangible and intangible motivation leads to the correct balance to motivate students successfully. 


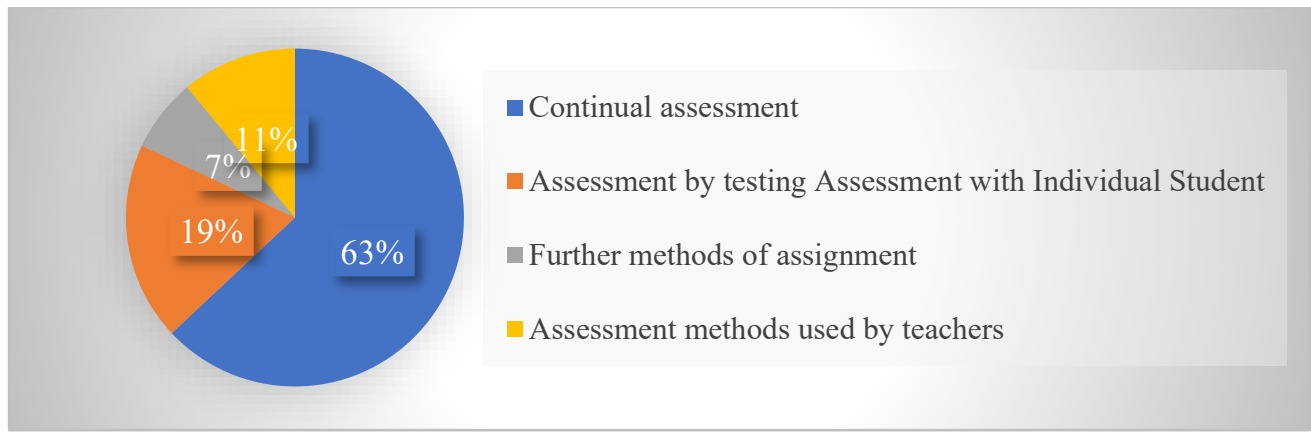

Figure 2. The methods you use to motivate the student in the classroom

Furthermore, A18 mentioned that "there isn't the structure of the methods used to motivate students in the college and university that I have taught. On the other hand, A 19 stated that:

"In my opinion, it is significant for teachers to reflect during the teaching and the preparation of the lesson inside the college or university. As an alternative, I can see some teachers spending their time on social media such as Facebook. While they should focus on update new methods of assessment and which methods are best of teaching based on the reflections".

A19 claimed similarly to A23: "In my view, the most vital key points that to make us effective during teaching are; the correct guideline for students, continues assessment and individual motivation for each student separately".

A11 stated, along with the closed question with students, and to obtain opinions of motivation factor to encourage students to approaches used in the classroom. The reflections are the keystone for teachers during the teachings sessions to get different communication techniques or gestures in the classroom, so they do feel motivated to accomplish their academic achievements.

From Figure 3, it becomes concise that there are factors affecting students learning and motivate them in the classroom better. By interpreting the data from graphic 3, this study has discovered that the students generate an optimistic expressive circumstance when the educator varieties complement the rate of $26 \%$ of 153 students. Additionally, $25 \%$ rate, which teachers are less motivated students when he/she inducements their attention. While $13 \%$ mentioned that poor communication will be leading to demotivate them. Finally, 18\% percentage stated when teachers teach with inspiration, thus, he/she gets students attention in the classroom effectively without screams with a loud voice.

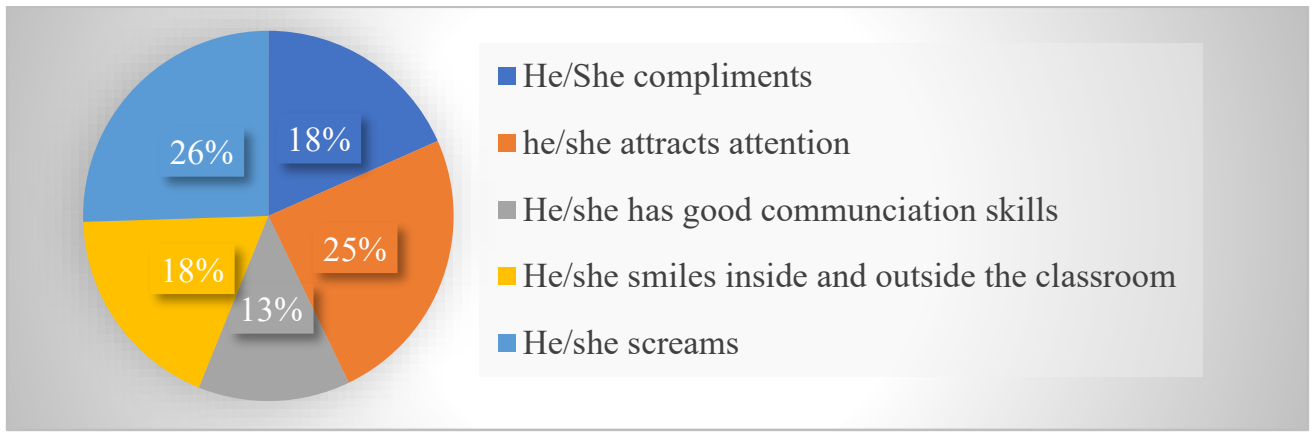

Figure 3. The types of communication skills from teachers make students better motivation 
Moreover, regarding the second research question from Graphic 4, it becomes brief when a researcher asked students on the questionnaire. "How is the teacher dealing with your needs in the classroom? $21 \%$ percentage of students responded that teacher doing well to deal with their needs in class. Nevertheless, at $43 \%$ rate, they responded he/she is very strict. Likewise, only $9 \%$ of students responded he/she too liberal, and $11 \%$ of students answered he/she hears a little. Lastly, 16\% answered he/she is very perseverant.

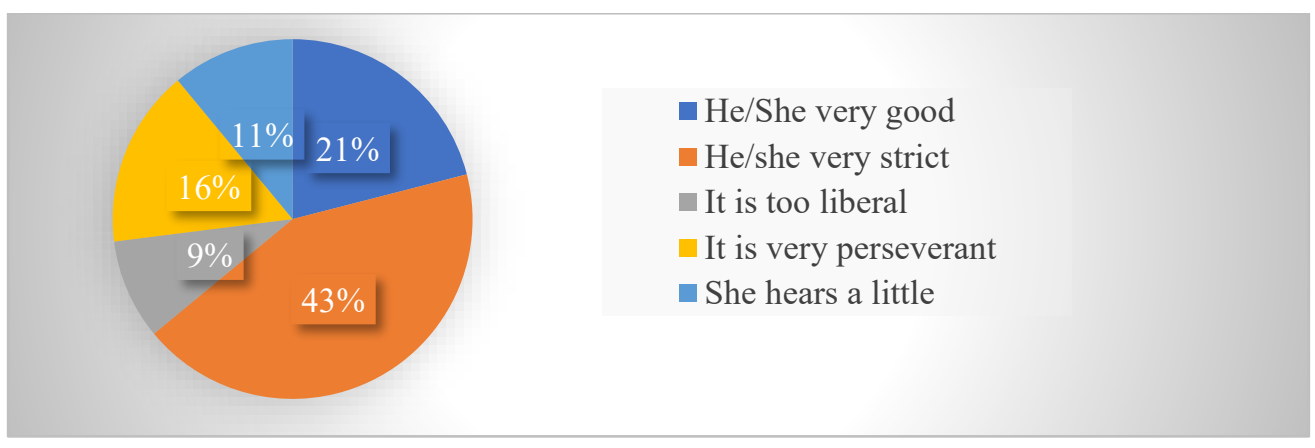

Figure 4. How is your Teacher in Classroom?

\section{The Conclusion and Discussion}

To put it briefly, this study has deliberated the validation of the challenges of the motivational factors that influence students in lecture is significant for the progress of the educational sector in the KRI. Unquestionably, teaching with pleasure is vital which facing challenges of motivational factors for teachers and unpledged undergraduates in the teaching space continuously give the problem to the humanity in the educational sector. Subsequently, the educator is earlier to students they have a propensity to do their greatest to encourage their awareness in college or university. Consequently, it is part of the teacher's performances, teaching style, and teaching with inspiration which are abilities that impacts teachers to motivate students in the classroom. Hence, educators' self-motivation and motivational factors are inspiring them to teach effectively and educator's encouragement the level of student's motivation in learning. These are the keystone in motivation which power a critical step in motivating students in the real environment to learn. On the other hand, this study has demonstrated that elementary teachers, college teachers and university teachers do their best to motivate students by teaching them. Thus, the moral communication skills of teachers, the factor involves in teaching styles, and teaching strategies within different techniques in the sessions are the most significant impacts on students' performance and their academic achievement. To conclude, according to the second research question teachers who teach with inspiration often motivate and encourage the students to make feel significant and valuable, which lead them to learn successfully. However, roughly most of the teachers apply different teaching approaches, and teaching styles and this according to the second research question growing student success, and achievement a good result. Finally, a successful teacher who has good knowledge about student psychologies, diverse personalities, atmosphere, incentive, enthusiasm, motivation and are key factors that enable students to change all negative influences that affect them in the teaching space. 


\section{References}

Anderman\& Midgely. (1998). The Motivation across the transition from middle school to high school: Theories and issues. Falmer Press Teachers' Library.

Adam, L \& William, J. (2009). Improving the strategies on intrinsic \& extrinsic motivation in education. Sage, London: Educational Research Journal.

Bernstein-Yamashiro, B., \& Noam, G. (2013). Teacher-student relationships: Toward personalized education. San Francisco, CA: Jossey-Bass/Wiley.

Blaikie, N (2000). Motivational Factors in high Education. $3^{\text {rd }}$ edition. Cambridge, Polity Press.

Bomia, L (1997). The Impact of Teaching Strategies on intrinsic motivation: Champaign, ERIC Clearinghouse on Elementary and Early Childhood Education.

Brooks, F. (1998). Improving elementary student engagement in the learning process through integrated thematic instruction. $3^{\text {rd }}$ Edition. Sanit Xavier University. Chicago.

Comte, R. (2000). The Art of Case Study Research: Perspective in Practice. Sage, London: Educational Research Journal 32: 21-179.

Crotty, M. (1998). The foundations of social research: Meaning and perspective in the research process. $1^{\text {st }}$ edition. London Sage.

Creswell, W. (2007). A motivational analysis of self-system processes. Chapter 11: Mixed methods procedures, pp. 208-227

Dev, K. (1997). Intrinsic motivation and academic achievement. Thousand Oaks. Sage. School Partnerships Tirana.

Dornyei, Z (2009). Creating a Motivating Classroom Environment. New Handbook of English Language Teaching. New York: Springer. Pp (65-289).

Guay et al. (2010). Intrinsic, identified, and controlled types of motivation. British Journal of Educational Psychology. (pp 52-128).

Gredler, Broussard and Garrison (2004). The roles of motivation in classroom. British Journal of Educational Psychology (pp 32-98).

Julie, G. (2008). Motivation in Educational Sectors. $2^{\text {nd }}$ edition London, Routledge. Sage.

Kayle M. (1998). Meta-Ethnography: Synthesizing Qualitative Studies. $1^{\text {ST }}$ edition. Open University Press; London: Sage.

LeCompte, F \& Schensul, K. (1999). Comprehensive criteria to judge validity and reliability of qualitative research within the realism paradigm. Qualitative Research, 3(3). $1^{\text {st }}$ edition New York: Free Press.

Mayer, J.D., Salovey, P. y Caruso, D.R. (2016). Emotional Intelligence: Theory, Findings, and implications. Psychological Inquiry, 15 (3),197

Murray, C., Kosty, D., \& Hauser-McLean, K. (2016). Social support and attachment to teachers: Relative importance and specificity among low-income children and youth of color. Journal of Psychoeducational Assessment, 34(2), 119-135.

Mortiboys, A. (2012). Teaching with emotional intelligence: A step-by-step guide for higher and further education professionals. London, UK: Routledge. 
Naqvi, I., Iqbal, M., \& Akhtar, S. N. (2016). The relationship between emotional intelligence and performance of secondary school teachers. Bulletin of Education \& Research, 38(1), 209- 224.

Vygotsky, L., \& Cole, M. (1978). Mind in society: The development of higher psychological processes. Cambridge, MA: Harvard University Press.

Watt, H., Carmichael, C., \& Callingham, R. (2017). Students' engagement profiles in mathematics according to learning environment dimensions: Developing an evidence base for best practice in mathematics education. School Psychology International, 38(2),166183. 